\title{
Based on the Beers Criteria 2019 Edition Over-the-Counter Drugs Risk Confirmation of Elderly Chinese
}

\author{
Yongyu Yang $\mathbb{D}^{1},{ }^{1}$ Lu Zhang $\mathbb{D}^{2,3}$ Yamin Huang $\mathbb{D}^{2,3}$ Hangxing Huang $\mathbb{D}^{2,3}$ \\ Shusen Sun $\mathbb{D}^{2,4,5}$ and Jian Xiao $\mathbb{i D}^{2,3}$ \\ ${ }^{1}$ Department of Pharmacy, The Second People's Hospital of Beihai, Beihai, Guangxi, China 536000 \\ ${ }^{2}$ Department of Pharmacy, Xiangya Hospital, Central South University, Changsha, Hunan, China 410008 \\ ${ }^{3}$ National Medical Center for Geriatrics, Xiangya Hospital, Central South University, Laboratory for Rational and Safe Use of Elderly, \\ Changsha, Hunan, China 410008 \\ ${ }^{4}$ Department of Pharmacy Practice, College of Pharmacy and Health Sciences, Western New England University, Springfeld, \\ MA 01119, USA \\ ${ }^{5}$ The Hunan Institute of Pharmacy Practice and Clinical Research, Changsha, Hunan 410008, China
}

Correspondence should be addressed to Shusen Sun; ssun@wne.edu and Jian Xiao; admanoas@163.com

Received 22 February 2021; Revised 25 May 2021; Accepted 5 August 2021; Published 25 August 2021

Academic Editor: Cristiano Capurso

Copyright (C) 2021 Yongyu Yang et al. This is an open access article distributed under the Creative Commons Attribution License, which permits unrestricted use, distribution, and reproduction in any medium, provided the original work is properly cited.

\begin{abstract}
Objective. To explore OTC (over-the-counter drugs) in Chinese community pharmacies often causes ADE (adverse drug event) in elderly patients. Methods. Use the drugs in the Beers Criteria 2019 potentially inappropriate medication use (PIM) list as search terms. Search for drugs registered on the National Medical Products Administration of China website before December 2019 to determine the drugs containing PIM active ingredients and, then, search the Chinese OTC selection and conversion catalog database to determine it as OTC. Two databases are considered to be the same drug if they have the same drug composition. Results. The incidence of PIM in elderly patients in our community is relatively high, and the management of OTC may be related to risk factors. Statistics found that 71 OTC contained the Beers Criteria ingredients, including 65 chemicals and six Chinese patent medicines. Varieties of compound preparations accounted for $78.9 \%$ and cold medicines accounted for $47.9 \%$. Conclusions. The high detection rate of the Beers Criteria in Chinese OTC suggests that medical practitioners in China, especially community pharmacists, should pay attention to the rational use of OTC in the elderly.
\end{abstract}

\section{Introduction}

Potentially inappropriate medication use (PIM) is considered a common cause of adverse health outcomes, and over-thecounter drugs (OTC) have contributed to the increased incidence of PIM [1]. A study of the use of OTC by the elderly in community pharmacies found that $95 \%$ of participants had at least one potential medication error, $80 \%$ of participants chose OTC, which may cause potential drug-drug interactions if taken with their current prescription drug treatment strategies [2]. American Geriatrics Society (AGS) Beers Criteria has now become an important evaluation standard for judging PIM in the elderly [3]. Hitherto, there is no study on the incidence of PIM in Chinese OTC based on the Beers
Criteria, so the variety and quantity of the Beers Criteria active ingredients in Chinese OTC are unknown.

The city and hospital levels are independent risk factors that cause PIM in elderly patients in China [4]. The incidence of PIM was higher among elderly patients in rural outpatient clinics and retirement communities than in outpatient clinics in large cities. At the same time, a large number of studies have shown that the incidence of PIM in elderly hospitalized patients in China is 50\%-70\% [5-7]. A survey of outpatient prescriptions in 79 hospitals in China with 6 major cities based on the Beers Criteria 2012 stated that the incidence of PIM was 15.8\%-23.0\% [4]. According to the Beers Criteria 2019 , a retrospective evaluation of 1,874 outpatients aged 65 years and older in first-tier cities in China, where the 
prevalence of PIM drugs was 35\% [8], while the incidence of elderly people living in senior care communities was $39.0 \%$ $60.6 \%[9,10] .57 \%$ of elderly patients with chronic diseases taking prescription drugs and OTC were unsafe to take OTC [11]. The PIM and the adverse reaction (ADR) of elderly patients with chronic diseases in the Chinese community are extremely significantly correlated $(r=0.716, P<0.01)$ [12]. Numerous relevant studies have shown that PIM drugs for elderly Chinese patients include proton pump inhibitors (PPIs) [10, 13-15], analgesic [9, 10, 12-14], and anticholinergic drugs $[8,10,13,14]$. In the elderly patients with ADR caused by PIM, the PIM drugs include analgesic, anticholinergic drugs, PPIs, Chinese patent medicine, and compound preparations $[12,13]$.

OTC have the characteristics of safety in application, stable quality, accurate curative effect, convenient use, etc., and are generally targeted at mild diseases, low cost, convenient purchase, and extensive clinical use. Then, patients often buy OTC by themselves, thinking that OTC are safe and do not pay attention to potential drug risks, and it is more common for the elderly [16, 17]. Self-medication of elderly patients, including OTC, can easily lead to $\operatorname{ADR}[18,19]$, PIM caused by the use of prescription drugs and OTC in elderly patients has attracted widespread attention $[16,17$, 20]. A cross-sectional study conducted by the Health Counseling Center of a teaching hospital in Brazil, according to the Beers Criteria 2015, 80.5\% of the elderly who selfmedicate will purchase prescription and OTC without the supervision of professionals. $55.5 \%$ of people used the drugs on the PIM list recognized by the Beers Criteria, and OTC accounted for $52.6 \%$ of these drugs [18]. In the elderly at risk of major adverse drug event (ADE), more than $50 \%$ of the events involve OTC [2].

According to statistics, only $45 \%$ of residents in China have a certain awareness rate of OTC [21]. Xu et al. [22] analyzed 45 cases of ADR caused by OTC in the hospital, and OTC accounted for $12.6 \%$ of all ADRs, and people over 60 accounted for $24.4 \%$. At present, PIM research in China is mostly limited to prescription drugs in hospitals or communities. It rarely involves self-medication of the elderly including OTC, especially some Chinese patent medicine and compound preparations $[12,23]$. How to evaluate and prevent PIM in OTC for the elderly is a matter of concern.

Therefore, this study is aimed to use the Beers Criteria 2019 to count the varieties of PIM active ingredients in Chinese OTC and explore the risks of PIM in Chinese OTC according to the Beers Criteria 2019.

\section{Methods}

Use the drugs in the Beers Criteria 2019 PIM list as search terms. Search for drugs registered on the National Medical Products Administration of China website (https://www.nmpa.gov.cn/) before December 2019 to determine the drugs containing PIM active ingredients and, then, search the Chinese OTC selection and conversion catalog database to determine it as OTC. Two databases are considered to be the same drug if they have the same drug composition.

\section{Results}

A total of 71 kinds of OTC containing active ingredients of PIM drugs were screened, including 65 kinds of chemicals, 56 kinds of compound preparations, and 6 kinds of Chinese patent medicines. Chinese patent medicines are Chinese and Western medicine compound preparations containing chlorpheniramine, and phenobarbital and scopolamine tablets contain two kinds of PIM ingredients. The classification of drugs is based on China's "National Basic Medical Insurance, Work Injury Insurance and Maternity Insurance Drug Catalog" (2019 Edition) [24]; there are the most varieties of cold medicine and digestive system. There are 6 kinds of Chinese patent medicines, all of which are Chinese and western medicine compound preparations (See Table 1). In addition, cold medications accounted for $47.9 \%$, of which PIM-containing active ingredients contained first-generation antihistamines, which accounted for $67.6 \%$ (48/71), and chlorpheniramine accounted for $39.4 \%$, followed by digestive system drugs, antipyretic analgesics, and nonsteroidal anti-inflammatory drugs (NSAIDs) (See Table 2).

\section{Discussion}

Statistics show that there are 56 kinds of compound preparations and 34 kinds of cold medicines in OTC containing PIM active ingredients. Cold medicines of OTC are widely used in China. A survey by the China OTC Association shows that cold medicines have the highest proportion of selfmedication among Chinese residents, accounting for $89 \%$ [21]. Among the 71 types of OTC we have counted, $47.9 \%$ are cold medicines, and six Chinese patent medicines are Chinese and Western compound preparations. Wang et al. [25] conducted a consolidated analysis of the relevant data in the "Annual Report on ADR Monitoring" issued by the National Medical Products Administration of China from 2009 to 2018, and the proportion of Chinese patent medicines was $10 \%-20 \%$. In 2011, Wu et al. [26] conducted information data mining research on ADR of Chinese and Western compound preparations, collected and retrieved reports on ADR cases caused by Chinese and Western compound preparation published in China from 2007 to 2010, established a database, and used statistics Method analysis; the results show that cold medicines are the most reported ADR, with the elderly accounting for $29.51 \%$. Cold medicines are mostly compound preparations and Chinese and Western compound preparations, which can easily cause ADR $[22,26]$ and severe ADR [19, 27]. Excessive medication has been the main cause of cold and Western compound preparations $\mathrm{ADR}$ or $\mathrm{ADE}$ [28]; the risk of $\mathrm{ADR}$ caused by Chinese and Western coordinated use or combination of drugs containing the same ingredients or with similar functions has attracted attention in China [29].

Statistics show that many OTCs contain ingredients with strong anticholinergic properties, including the firstgeneration antihistamines, chlorpheniramine, promethazine, diphenhydramine, and dimenhydrinate. In a small-sample statistic in China, PIM caused $15.5 \%$ of the first-generation antihistamines in ADR, and the proportion of compound 
TABLE 1: Varieties of OTC drugs containing PIM ingredients.

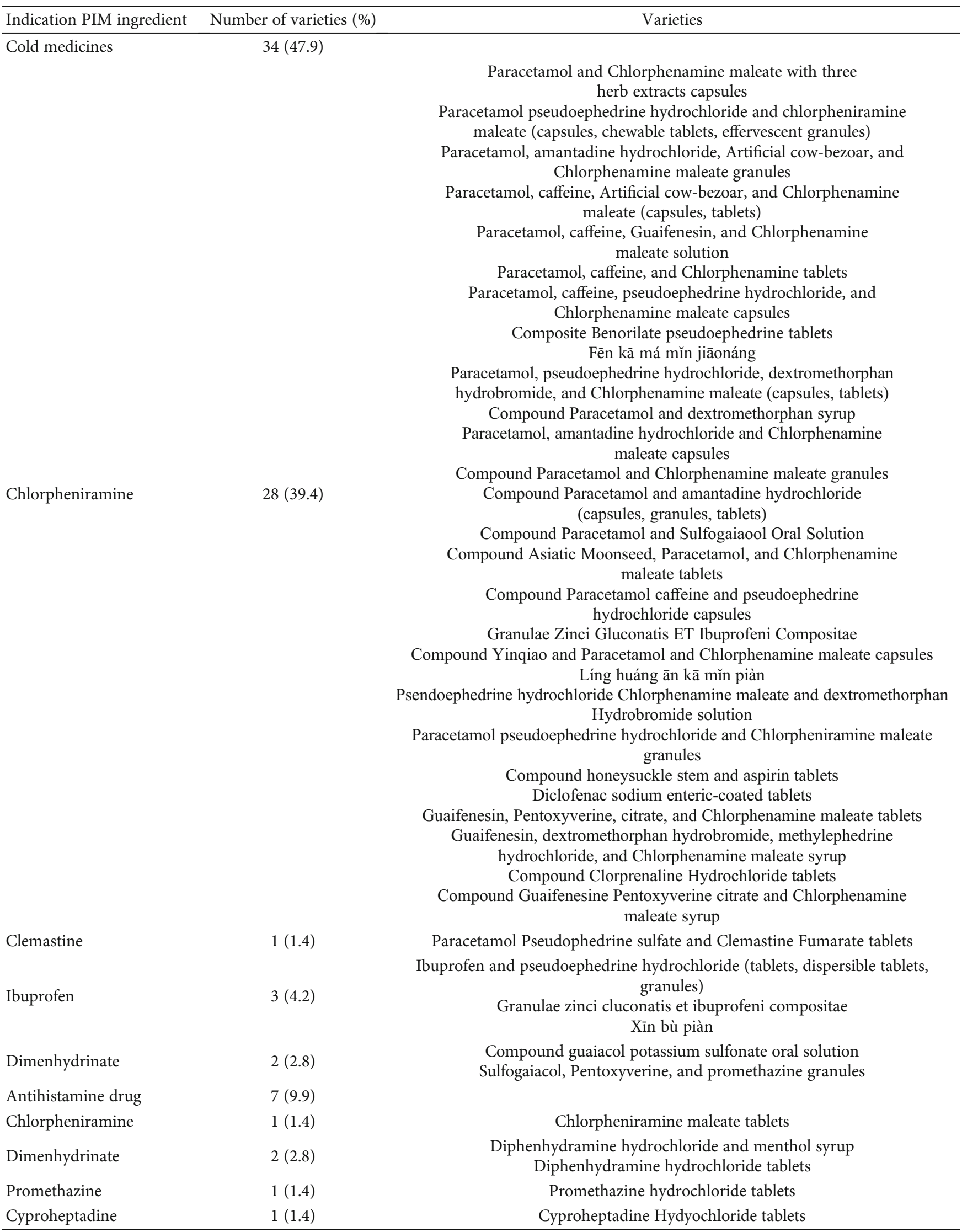


TABLE 1: Continued.

\begin{tabular}{lc}
\hline Indication PIM ingredient & Number of varieties (\%) \\
\hline Triprolidine & $1(1.4)$ \\
Dimenhydrinate & $1(1.4)$ \\
Digestive system drugs & $15(21.1)$
\end{tabular}

A. belladonna

$12(16.9)$

Omeprazole
Hyoscyamine
Antipyretic analgesics and
NSAIDs
Ibuprofen
Diclofenac
Ketoprofen
Naproxen
Diphenhydramine
Chlorzoxazone
Triprolidine
Nervous system medicines
Scopolamine
Phenobarbital
Chinese patent medicines

Chlorpheniramine

$6(8.5)$
Varieties

\author{
Triprolidine hydrochloride capsules \\ Dimenhydrinate (tablets, Buccal tablets)
}

Aluminum Magnesium and Belladonna tablets Compound Magnesium Trisilicate and sodium bicarbonate tablets Compound Belladonnate and Aluminium hydroxide (tablets, powder) Compound Glycyrrhiza, Bismuth, and Magnesium tablets Compound Aloe and vitamin $U$ tablets Compound Aluminium hydroxide tablets Aluminium hydroxide gel

Compound Corydalis tuber and Aluminium hydroxide tablets Compound Belladonnate and Aluminium hydroxide (tablets, powder) Medicated Leaven, Rhubarb, Sodium bicarbonate, and Aluminium hydroxide capsules

Vitamin U, Belladonna, and Aluminium (capsules II, capsules, dispersible tablets) Vitamin U, Aluminium hydroxide, and Magnesium Trisilicate (capsules, tablets, tablets II)

Omeprazole enteric-coated capsules Omeprazole magnesium enteric-coated tablets Raceanisodamine tablets

Ibuprofen (tablets, dispersible tablets, capsules, syrup, Oral solution, Chewables tablets, Effervescent tablets) Ibuprofen arginine tablets Diclofenac potassium tablets Ketoprofen (tablets, capsules)

Naproxen (tablets, capsules, sustained release capsules, sustained release tablets, enteric-coated microgranules capsules)

Ān fên lā míng piàn

Compound Chlorzoxazone tablets

Paracetamol, Triprolidine hydrochloride, and pseudoephedrine hydrochloride tablets

Phenobarbital and scopolamine hydrobromide tablets

Wéi C yín qiào kēlì, Wéi $\mathrm{C}$ yín qiào piàn

Gănmào ān piàn

Hāi kè píng jiāonáng

Hāi tè líng jiāonáng, Hāi tè líng piàn, Hāi tè líng kēlì

Bíyán kāng piàn

Cāng é bíyán piàn

OTC: over-the-counter; PIM: potentially inappropriate medication; NSAIDs: nonsteroidal anti-inflammatory drugs. Some of the drugs were specific to China, and we translated the names of these drugs through Google translation.

preparations containing chlorpheniramine maleate was the highest [13]. The first-generation antihistamines are lipophilic drugs, which easily cross the blood-brain barrier and interact with many drugs. Due to anticholinergic side effects, the Beers Criteria included it on the PIM list, but still widely used in the elderly [30, 31]. The combination of prescription drugs and anticholinergic OTC in the elderly at the same time increases the burden of anticholinergic, leading to the risk of $\mathrm{ADE}$ and other negative consequences [15]. It is not recommended to use drugs with significant anticholinergic side effects [32].

The main category of ADR caused by OTC is NSAIDs [22], which are not only the most self-medication drugs for elderly patients $[18,19,33,34]$, but also the drugs most related to drug interactions [18]. NSAIDs may not only cause $\mathrm{ADE}$ due to drug interactions but also increase the risk of cardiovascular disease [35], causing dizziness, falls in the elderly, the occurrence or aggravation of cardiovascular 
TABLE 2: OTC pharmaceutical preparations and proportion.

\begin{tabular}{|c|c|c|c|c|}
\hline \multirow{2}{*}{ Drugs } & \multicolumn{2}{|c|}{ Preparation classes } & \multirow{2}{*}{ Total } & \multirow{2}{*}{ Proportion (\%) } \\
\hline & Simple & Compound & & \\
\hline Anticholinergic drug & & & 60 & 84.5 \\
\hline \multicolumn{5}{|c|}{ The first-generation antihistamines } \\
\hline Chlorpheniramine & 1 & 34 & & \\
\hline Dimenhydrinate & 1 & 2 & & \\
\hline Diphenhydramine & 2 & 1 & & \\
\hline Promethazine & 1 & & & \\
\hline Clemastine & & 1 & & \\
\hline Cyproheptadine & 1 & & & \\
\hline Triprolidine & 1 & 1 & & \\
\hline \multicolumn{5}{|l|}{ Antispasmodic } \\
\hline A. belladonna & & 12 & & \\
\hline Hyoscyamine & 1 & 1 & & \\
\hline Digestive system drugs & & & 2 & 2.8 \\
\hline Omeprazole & 2 & & & \\
\hline Analgesic & & & 9 & 12.7 \\
\hline \multicolumn{5}{|c|}{ Oral nonselective COX inhibitors } \\
\hline Ibuprofen & 2 & 3 & & \\
\hline Diclofenac & 1 & & & \\
\hline Ketoprofen & 1 & & & \\
\hline Naproxen & 1 & & & \\
\hline \multicolumn{5}{|l|}{ Skeletal muscle relaxants } \\
\hline Chlorzoxazone & & 1 & & \\
\hline Total & 15 & 56 & 71 & 100 \\
\hline
\end{tabular}

OTC: over-the-counter; COX: cyclooxygenase.

disease [15], and increasing the risk of dementia and death in elderly patients [36]. In 2015, the Food and Drug Administration (FDA) issued a warning that NSAIDs increase the risk of heart disease and stroke [37]. On the other hand, NSAIDs can easily cause gastrointestinal system damage $[19,34]$, and the use of the elderly is more likely to cause serious gastrointestinal adverse reactions [38]. High-risk factors for PIM include age $\geq 75$ years, oral corticosteroids, anticoagulants, or antiplatelet drugs $[39,40]$. If there are no professionals to conduct medication evaluation, the use of NSAIDs by people with high-risk factors will increase the risk of ADE [18].

Elderly self-medication is universal $[18,41]$. The important specific types of PIM for the elderly in prescription drugs and OTC are drug-drug and drug-disease interactions [40]. The causes of PIM in elderly patients in the Chinese community include not only multiple comorbidities and multiple medications but also many factors such as self-purchasing medications, long-term replacement medications, and repeated medications [42]. A variety of OTC contain PIM active ingredients. The use of OTC in elderly patients can easily lead to repeated medications and increase the risk of potential drug overdose and possible drug-drug interactions, leading to ADR $[8,16,18]$. The ADR of PIM is mostly a cumulative effect $[18,21]$, which can cause many adverse consequences in elderly patients. Compared with elderly patients without PIM, the risk of hospitalization in elderly patients with one type of PIM is 1.13 times, the risk of hospitalization with two types of PIM is 1.27 times, and the risk increases to 1.35 times with three types of PIM [43]. In addition, PIM in elderly patients can also lead to an increase in mortality. Compared with elderly patients without PIM, elderly patients with $\geq 1$ PIM have an increased risk of death by 1.44 times [44].

Elderly chronic patients need more pharmacist intervention when using OTC [11]. As far as we know, Chinese elderly people lack reliable knowledge of multiple drugs $[28,32]$. In China, a team of pharmacists and family doctors has little intervention in the rational use of OTC for elderly patients. How to ensure the safety of OTC for the elderly is a question worthy of further consideration for medical staff.

\section{Conclusion}

The high detection rate of the Beers Criteria in Chinese OTC suggests that medical practitioners in China, especially community pharmacists, should pay attention to the rational use of OTC in the elderly.

\section{Data Availability}

The data can be obtained from the corresponding author for appropriate reasons. 


\section{Conflicts of Interest}

All authors declare that they have no conflict of interests.

\section{Authors' Contributions}

Y.Y.Y., S.S.S., and J.X. drafted the manuscript. L.Z. conducted a literature survey. H.X.H., L.Z., and Y.M.H. were responsible for the statistical analysis. All authors participated in the revision of the manuscript.

\section{Acknowledgments}

The study was supported by the following research funds: (1) Changsha Natural Science Foundation of 2020 (Number: kq2007039). (2) National Clinical Research Center for Geriatric Disorders, Xiangya Hospital (XYYYJSTG-15). (3) Parallel and Distributed Processing for the Stable Support Project of the National Defense Science and Technology Key Laboratory (WDZC20205500121). (4) The Fundamental Research Funds for the Central Universities of Central South University (2021zzts1040). (5) Science and Technology Development Center of Chinese Pharmaceutical Association (CMEI2021KPYJ (JZYY) ) 00301).

\section{References}

[1] N. Mielke, D. Huscher, A. Douros et al., "Self-reported medication in community-dwelling older adults in Germany: results from the Berlin initiative study," BMC Geriatrics, vol. 20 , no. 1 , p. $22,2020$.

[2] J. A. Stone, C. A. Lester, E. A. Aboneh, C. H. Phelan, L. L. Welch, and M. A. Chui, "A preliminary examination of overthe-counter medication misuse rates in older adults," Research in Social \& Administrative Pharmacy, vol. 13, no. 1, pp. 187192, 2016.

[3] T. L. Griebling, "Re: American Geriatrics Society 2019 updated AGS beers criteria ${ }^{\circledR}$ for potentially inappropriate medication use in older adults," The Journal of Urology, vol. 202, no. 3, p. 438, 2019.

[4] J. Wu, A. Lu, L. Zhang, Y. Zuo, and Y. Jia, "Study of clinical outcome and prognosis in pediatric core binding factor-acute myeloid leukemia," Zhonghua Xue Ye Xue Za Zhi, vol. 40, no. 1, pp. 52-575, 2019.

[5] X. Zhang, S. Zhou, K. Pan et al., "Potentially inappropriate medications in hospitalized older patients: a cross-sectional study using the Beers 2015 criteria versus the 2012 criteria," Clinical Interventions in Aging, vol. 12, pp. 1697-1703, 2017.

[6] P. Wang, Q. Wang, F. Li, M. Bian, and K. Yang, "Relationship between potentially inappropriate medications and the risk of hospital readmission and death in hospitalized older patients," Clinical Interventions in Aging, vol. 14, pp. 1871-1878, 2019.

[7] H. Li, S. Pu, Q. Liu et al., "Potentially inappropriate medications in Chinese older adults: the beers criteria compared with the screening tool of older persons' prescriptions criteria," Geriatrics \& Gerontology International, vol. 17, no. 11, pp. 1951-1958, 2017.

[8] Y. Huang, L. Zhang, X. Huang, K. Liu, Y. Yu, and J. Xiao, "Potentially inappropriate medications in Chinese community-dwelling older adults," International Journal of Clinical Pharmacy, vol. 42, no. 2, pp. 598-603, 2020.
[9] X. B. Li and P. Wang, "Potentially inappropriate medication among the elderly in Zhaitang community and its related factors," Chinese Journal of Multiple Organ Diseases in the Elderly, vol. 19, no. 5, pp. 340-344, 2020.

[10] Q. Y. Yang, X. Liu, Q. Pan, X. K. Xu, S. H. Li, and Y. Zhu, "Medication risk and safety evaluation for elderly patients in the nursing community by 2019 Beers criteria," World Clinical Drugs, vol. 40, no. 9, pp. 664-670, 2019.

[11] K. Guirguis, "The use of nonprescription medicines among elderly patients with chronic illness and their need for pharmacist interventions," The Consultant Pharmacist, vol. 25, no. 7, pp. 433-439, 2010.

[12] X. Q. Li, H. Y. Yang, F. F. Mao, Y. Chen, and X. Luo, "Evaluate potentially inappropriate medication in elderly patients of chronic diseases with different diseases from community by the new Beers," World Clinical Drugs, vol. 36, no. 9, pp. 618622,2015

[13] B. Xiang, J. Wang, D. M. Deng, H. Pan, Y. Hou, and W. Wang, "Evaluation and analysis of adverse drug reactions caused by inappropriate medication in elderly hospitalized patients," Shanghai Medical \& Pharmaceutical Journal, vol. 40, no. 13, pp. 36-39, 2019.

[14] W. L. Xi, W. Jiang, Z. Z. Li, and Y. J. Shi, "Evaluation of potential inappropriate medications in rural elderly patients of chronic disease based on 2015 Beers criteria," Journal of Medical Forum, vol. 39, no. 8, pp. 56-60, 2018.

[15] F. Li, S. Z. Wang, Z. H. Shi, L. L. Sun, and J. H. Zhang, "Evaluation of medication in community elderly patients based on 2015 updated Beers criteria," Chinese Journal of New Drugs and Clinical Remedies, vol. 37, no. 3, pp. 173-176, 2018.

[16] O. Abraham, L. Schleiden, and S. M. Albert, "Over-the-counter medications containing diphenhydramine and doxylamine used by older adults to improve sleep," International Journal of Clinical Pharmacy, vol. 39, no. 4, pp. 808-817, 2017.

[17] J. M. Cheung, D. J. Bartlett, C. L. Armour, J. G. Ellis, and B. Saini, "People with insomnia: experiences with sedative hypnotics and risk perception," Health Expectations, vol. 19, no. 4, pp. 935-947, 2016.

[18] S. B. V. Oliveira, S. C. C. Barroso, M. A. C. Bicalho, and A. M. M. Reis, "Profile of drugs used for self-medication by elderly attended at a referral center," Einstein (Sao Paulo), vol. 16, no. 4, article eAO4372, 2018.

[19] Y. M. Cai and H. Fang, "Analysis of 1005 adverse drug reaction reports in our hospital," China Pharmacy, vol. 26, no. 11, pp. 1509-1513, 2015.

[20] M. J. Koronkowski, T. P. Semla, K. E. Schmader, and J. T. Hanlon, "Recent literature update on medication risk in older adults, 2015-2016," Journal of the American Geriatrics Society, vol. 65, no. 7, pp. 1401-1405, 2017.

[21] H. L. Bai and R. Shao, "Evaluation on economic evaluation of non-prescription drugs," China Journal of Pharmaceutical Economics, vol. 14, no. 10, pp. 47-51, 2019.

[22] J. D. Xu, Q. Chen, J. J. Yi, Z. Li, and X. Zhang, "Analysis of 45 cases of OTC drug induced ADR," China Pharmacy, vol. 28, no. 11, pp. 1486-1489, 2017.

[23] R. Wang, D. H. Guo, Y. Y. Li, and H. Shi, "Evaluation and application research of different criteria for potentially inappropriate medications in elderly outpatient prescriptions," Chinese Journal of Pharmacoepidemiology, vol. 1, pp. 30-35, 2019.

[24] National Medical Insurance Administration, "Notice on Issuing the "National Basic Medical Insurance, Work Injury 
Insurance and Maternity Insurance Drug Catalog",” August 2019, http://www.nhsa.gov.cn/art/2019/8/20/art_37_1666 .html.

[25] D. Wang, J. T. Ren, D. Dong, L. Peng, and W. Liu, “Trend analysis of ten-year annual reports on adverse drug reaction monitoring," Chinese Journal of Pharmacovigilance, vol. 17, no. 5, pp. 276-283, 2020.

[26] J. R. Wu, L. Dong, B. Zhang, P. Wang, and Y. JingZi, "Research on data analysis of adverse drug reactions induced by compound preparation of Chinese-western medicines," China Licensed Pharmacist, vol. 8, no. 12, pp. 10-12+15, 2011.

[27] National Medical Products Administration, "Adverse Drug Reaction Information Bulletin (No. 32) Concerned about the safety of Vitamin C Yinqiao Tablets, a compound preparation of Chinese and Western medicines," September 2010, https:// www.nmpa.gov.cn/directory/web/nmpa/xxgk/yjjsh/ypblfytb/ 20100919162601498.html.

[28] S. N. Huang, M. Guo, L. Y. Chang, and B. H. Yu, “Adverse reactions and rational drug use analysis of combination of traditional Chinese and Western medicine in treatment of colds," Pharmacy and Clinics of Chinese Materia Medica, vol. 6, no. 3, pp. 52-55, 2015.

[29] National Medical Products Administration, "Adverse Drug Reaction Information Bulletin (Issue 67) Concerned about the medication risks of Chinese and Western medicine compound preparations," June 2015, https://www.nmpa.gov.cn/ directory/web/nmpa/yaopin/ypjgdt/20150626151901886 .html.

[30] L. L. Jensen, J. Rømsing, and K. Dalhoff, "A Danish survey of antihistamine use and poisoning patterns," Basic \& Clinical Pharmacology \& Toxicology, vol. 120, no. 1, pp. 64-70, 2017.

[31] H. Cho, J. Choi, Y. S. Kim et al., "Prevalence and predictors of potentially inappropriate prescribing of central nervous system and psychotropic drugs among elderly patients: a national population study in Korea," Archives of Gerontology and Geriatrics, vol. 74, pp. 1-8, 2018.

[32] Z. Ma, C. Zhang, X. Cui, and L. Liu, "Comparison of three criteria for potentially inappropriate medications in Chinese older adults," Clinical Interventions in Aging, vol. 14, pp. 6572,2018

[33] C. Z. Zhang, Z. L. Li, J. Chen, and S. Jiang, "Investigation of 41 cases of non-steroidal anti-inflammatory drugs related adverse reactions/adverse events reports," Chinese Journal of Pharmacoepidemiology, vol. 22, no. 2, pp. 72-73, 2013.

[34] A. Berreni, F. Montastruc, E. Bondon-Guitton et al., "Adverse drug reactions to self-medication: a study in a pharmacovigilance database," Fundamental \& Clinical Pharmacology, vol. 29, no. 5, pp. 517-520, 2015.

[35] D. M. Qato, J. Wilder, L. P. Schumm, V. Gillet, and G. C. Alexander, "Changes in prescription and over-the-counter medication and dietary supplement use among older adults in the United States, 2005 vs 2011," JAMA Internal Medicine, vol. 176, no. 4, pp. 473-482, 2016.

[36] C. Fox, K. Richardson, I. D. Maidment et al., "Anticholinergic medication use and cognitive impairment in the older population: the medical research council cognitive function and ageing study," Journal of the American Geriatrics Society, vol. 59, no. 8, pp. 1477-1483, 2011.

[37] U.S. FOOD \& DRUG ADMINISTRATION, "FDA Drug Safety Communication: FDA strengthens warning that nonaspirin nonsteroidal anti-inflammatory drugs (NSAIDs) can cause heart attacks or strokes," July 2015, https://www.fda .gov/drugs/drug-safety-and-availability/fda-drug-safetycommunication-fda-strengthens-warning-non-aspirinnonsteroidal-anti-inflammatory.

[38] RxList, “IBUPROFEN INDICATIONS," May 2020, https:// www.rxlist.com/ibuprofen-drug.htm\#indications.

[39] By the American Geriatrics Society 2015 Beers Criteria Update Expert Panel, "American Geriatrics Society 2015 Updated beers criteria for potentially inappropriate medication use in older adults," Journal of the American Geriatrics Society, vol. 63, no. 11, pp. 2227-2246, 2015.

[40] J. T. Hanlon, S. Perera, A. B. Newman et al., "Potential drugdrug and drug-disease interactions in well-functioning community-dwelling older adults," Journal of Clinical Pharmacy and Therapeutics, vol. 42, no. 2, pp. 228-233, 2017.

[41] F. Jafari, A. Khatony, and E. Rahmani, "Prevalence of selfmedication among the elderly in Kermanshah-Iran," Global Journal of Health Science, vol. 7, no. 2, pp. 360-365, 2015.

[42] W. Q. Zhang, "Analysis of 128 cases of drug reaction in the elderly in Tianlin community of Shanghai," Applied Journal of General Practice, vol. 4, pp. 337-338, 2007.

[43] O. Reich, T. Rosemann, R. Rapold, E. Blozik, and O. Senn, "Potentially inappropriate medication use in older patients in Swiss managed care plans: prevalence, determinants and association with hospitalization," PLoS One, vol. 9, no. 8, article e105425, 2014.

[44] M. M. do Nascimento, J. V. Mambrini, M. F. Lima-Costa, J. O. A. Firmo, S. W. V. Peixoto, and A. I. de Loyola Filho, "Potentially inappropriate medications: predictor for mortality in a cohort of community-dwelling older adults," European Journal of Clinical Pharmacology, vol. 73, no. 5, pp. 615-621, 2017. 